\title{
The Use of Instruments by Iranian Endodontics and General Practioners
}

\author{
Farokh Gisour Elham ${ }^{1, *}$ and Zarmehi Sedigheh ${ }^{2}$ \\ ${ }^{I}$ Kerman Dental Faculty, Peadiatric Department, Kerman, Iran \\ ${ }^{2}$ Kerman Dental and Oral Diseases Research Center and Kerman Dental Faculty, Iran
}

\begin{abstract}
Aim: The current clinical practice of endodontics involves utilization of a variety of new technological advances and materials. Technologies available for use in endodontic offices today include battery or electric motors using NiTi rotary file systems, new generation of electronic apex locators (EALs), improved digital radiographic sensors, surgical microscopes, and ultrasonic units. The aim of this study was to determine the prevalence and use of newer technologies among Iranian dental practitioners.

Materials and methods: The population under study included the dental practitioners participating in the 49th and 50th Congress of Dentistry, who were selected with a simple sampling method. Data was collected by questionnaires which were completed by the participants in an anonymous manner. The contingency table and chi-squared test were used for data analysis by SPSS 13.5 software.

Results: A total of 700 dental practitioners participated in the study; NiTi rotary systems were used by $50.1 \%$; electronic apex locators were often employed by $46.3 \% ; 21.7 \%$ reported that ultrasonic units were often used. Only $1.1 \%$ frequently used surgical microscopes. Males and females differed with respect to the use of newer technologies $(\mathrm{P}<0.05)$.

Conclusion: Based on the results of the present study, it seems necessary for dentists to take part in continuing dental education programs related to the newer technologies to improve their knowledge and practice.
\end{abstract}

Keywords: Newer technologies, NiTi File, Endodontic.

\section{INTRODUCTION}

There have been great advances in the design and manufacture of dental materials and equipment in recent years, parallel with advances in other fields. In the endodontic field, there have been great changes in the techniques and systems used [1]. The use of better and more effective equipment can improve treatment outcome and shorten the duration of treatment sessions [2].

The use of NiTi rotary instruments, endodontic microscopes, digital imaging techniques, canal obturation systems and biocompatible sealing agents have improved treatment outcomes. The use of new high-tech equipment has simplified treatment procedures and can prove beneficial for patients with complex systemic conditions and the elderly, making the treatment outcome more predictable $[3,4]$.

Several studies have shown the superiority of NiTi files over conventional instruments used for shaping the root canals [5]. In 2003, Molven et al. reported a large number of root canal treatment cases with effective canal obturations obtained using NiTi rotary techniques [6].

Several studies have evaluated the acceptance of new endodontic techniques among dental practitioners in several countries, including Denmark, Australia and India [7, 8]. In 2007 Brian et al. showed in a study in India that $19.7 \%$ of

*Address correspondence to this author at the Kerman Dental Faculty, Peadiatric Department, Kerman, Iran; Tel: 00989151689178; Fax:00983412118073; Emails: E_1379farokh@yahoo.com, farokhelham@yahoo.com dental practitioners used digital radiographic techniques, with the general dental practitioners comprising $73 \%$ of the users [9]. A study by Bjorndal et al. in 2005 showed that $18 \%$ of dental practitioners in Denmark used hand NiTi instruments [10]. Furthermore, the results showed that EAL (electronic apex locators) and soft gutta-percha were used by $19 \%$ of the dental practitioners $[11,12]$.

In 2004 Arab-chirani et al. evaluated the clinical use of NiTi rotary instruments. The results showed that all the undergraduate dental students should be instructed in the use of NiTi rotary instruments and these methods have a significant role in and central importance for endodontic treatment and educational courses in France [13].

In 2008 Tay et al. evaluated the use of new technologies by general dental practitioners in New Zealand. The results showed that apex locators $(81.4 \%)$ and intraoral cameras $(49.6 \%)$ had the highest application rates. Male dental practitioners used implant systems (41.6 vs. $24.1 \%$ ) and intraoral cameras $(53.6 \%$ vs. $39.8 \%)$ more than female dental practitioners. The abilities and capabilities of the dental practitioners were reported to be the most important factors determining the use of new technologies in New Zealand [14].

In 2009 Lee et al. carried out a study to determine the rate of use of the new endodontic materials and technologies in the United States and concluded that $82 \%$ of the dental practitioners still used hand filing techniques. Lateral and continuous wave techniques were the most commonly used obturation techniques. A total of $72 \%$ of the participants 
used digital radiographic techniques; $45 \%$ used electron microscopes and $97 \%$ used ultrasonic units. They finally concluded that new endodontic technologies are used with greater frequency in recent years $[15,16]$.

Peciuliere et al. carried out a review study in 2009 on the attitude of general dental practitioners toward endodontic standards and acceptance of new technologies, and concluded that there are differences between the daily routines of dental practitioners and academic instructions in various countries. A large number of dental practitioners violated the basic principles of endodontic treatment. The most prominent finding of the study was the negative attitude of general dental practitioners toward acceptance of new endodontic techniques. The results confirmed the technical difficulty of endodontic treatment and the sub-optimal quality of the treatments rendered by general dental practitioners. The study showed the importance of continuing dental education programs to improve the knowledge of general dental practitioners [17].

Furthermore, Koch et al. reported in 2009 in Sweden that $70 \%$ of dental practitioners who had received instructions about new endodontic techniques used rotary systems to prepare root canals; however, only $6 \%$ of dental practitioners who had not received such instructions used rotary systems [18]. No such studies have ever been carried out in Iran.

Studies have shown that every new technique has a low acceptance rate when it is introduced and only a limited number of people have a positive attitude toward new techniques $[17,19]$. Since no studies to date have evaluated the rate of the use of new endodontic techniques by dental practitioners in Iran and since endodontics is currently associated with new materials and methods, the present study evaluated the acceptance rate of new endodontic materials and techniques and the factors influencing their adoption.

\section{MATERIALS AND METHODS}

The subjects in the present cross-sectional descriptiveanalytical study consisted of the dental practitioners participating in the 49th and 50th International Congress of Dentistry in Tehran. The subjects were selected by simple random sampling method. An anonymous researcher- designed questionnaire was used for the purpose of the study, which included the following: demographic data (gender, age, year of graduation) and some questions regarding the use of new endodontic materials and methods, such as surgical microscopes, ethyl chloride spray, loops, transillumination, digital radiography, apex locators, NiTi rotary files, electric motors, ultrasonic devices, high-taper gutta-percha, intraoral cameras, local anesthetic injection techniques, Thermafil technique for canal obturation, and MTA. In order to evaluate validity and reliability of the questionnaire 10 endodontists and pedodontists were asked to fill in the questionnaire as a control. Then the questionnaires were collected and evaluated by a statistical consultant to validate the questionnaire. The questionnaire proved to be appropriately valid. In the second stage, the questionnaires were distributed among 20 dental practitioners who had given their consent to take part in the study to evaluate the reliability of the questionnaire. The reliability of the questionnaire was evaluated by a statistical consultant after they were collected. The Cronbach's alpha coefficient showed that the questionnaire was appropriately reliable. Subsequent to editing and prioritizing the questions the final questionnaire, which consisted of 16 questions and some demographic data, was prepared and completed and then distributed among the subjects. An instructed individual distributed the questionnaires a few minutes before one of the Congress sessions among 824 participants of the Congress, who had volunteered to fill in the questionnaires and asked them to return the questionnaires at the end of the Congress. A total of 700 (84.9\%) of the questionnaires were returned. After data collection, data was coded and the mean questionnaire score was taken into account in order to better evaluate the answers to the questions (Each 'yes' received a score of 1 and each 'no' received a score of 'zero'. Then the total score of the use of new materials and techniques was calculated. Contingency tables and chi-squared test were used to evaluate the relationship between the use of new endodontic instruments and techniques. In addition, means and standard deviations were used to express frequencies of demographic variables of the participants. Data was analyzed by ver. 13.5 of SPSS statistical software.

\section{RESULTS}

In the present study 824 questionnaires were distributed, of which $700(84.9 \%)$ questionnaires were retuned. Males and females comprised 245 and 452 of the participants, respectively. The greatest and lowest number of participants had gradated during 1998-2009 and 1958-1967, respectively. The results showed that the mean number of root canals treated during a week ranged between zero and 80 canals. The greatest numbers of root canals treated, in decreasing order, were reported to be in groups 0-4, 5-14 and 15-25, respectively. Tables 1 and 2 show the rates of the use of new endodontic instruments and techniques separately for gender and educational levels (general practitioners vs. specialists), respectively.

The highest positive response to the use of instruments was related to NiTi rotary files with $50.1 \%$ (348 participants) using them. The lowest response was related to surgical microscopes with only $1.1 \%$ (8 participants) using them. There were significant differences in responses to use loop for magnification, digital radiography, Niti rotary file ,electric motor for Niti rotary file, oral camera, Injection technique (Obtura) for canal obturation, Use of MTA in apicoectomy procedures (between males and females ( $\mathrm{p}$ value $<0.05)$ There were significant differences in responses to all the questions in relation to the academic degree (general practitioner vs. specialist) except using surgical microscop, oral camera, injection technique (obtura)for canal obturation and centeral heating technique(thermafil) for canal obturation.

The results of the present study showed a significant relationship between the use of new endodontic instruments and treatment modalities and gender $(\mathrm{P}=0.007)$. Females used new techniques more frequently than males.

There was a significant relationship between the use of new endodontic instruments and techniques and being general practitioners and endodontists $(\mathrm{P}=0.001)$; in other words, the highest and lowest rates of use were observed in endodontists and general practitioners, respectively. 
Table 1. Frequencies (Percentages) of the Use of New Endodontic Instruments and Techniques Separately in Relation to Gender

\begin{tabular}{|c|c|c|c|c|c|c|c|}
\hline \multirow{2}{*}{ Question } & \multicolumn{2}{|c|}{$\begin{array}{c}\text { Total } \\
\text { (Male and Female) }\end{array}$} & \multicolumn{2}{|c|}{ Man } & \multicolumn{2}{|c|}{ Female } & \multirow[b]{2}{*}{$\begin{array}{c}\text { P- } \\
\text { Value }\end{array}$} \\
\hline & Yes & No & Yes & No & Yes & No & \\
\hline & $\mathrm{N}(\%)$ & $\mathrm{N}(\%)$ & $\mathrm{N}(\%)$ & $\mathrm{N}(\%)$ & $\mathrm{N}(\%)$ & $\mathrm{N}(\%)$ & \\
\hline Surgical microscope & $8(1.1)$ & $689(98.9)$ & $3(1.2)$ & $242(98.8)$ & $5(1.1)$ & 447 (98.9) & 0.89 \\
\hline Loops for magnification & $106(15.2)$ & $590(84.8)$ & $23(9.4)$ & $222(90.6)$ & $83(18.4)$ & $368(81.6)$ & 0.002 \\
\hline Transillumination to detect cracks in tooth structure & $134(19.3)$ & $560(80.7)$ & $37(15.1)$ & $208(84.9)$ & $97(21.6)$ & $352(78.4)$ & 0.04 \\
\hline Digital radiographic technique & $214(30.9)$ & $478(69.1)$ & $61(25.0)$ & $183(75.0)$ & $153(34.2)$ & $295(65.8)$ & 0.013 \\
\hline Apex locator to determine working length & $322(46.3)$ & $373(53.7)$ & $108(44.1)$ & $137(55.9)$ & $214(47.6)$ & $236(52.4)$ & 0.38 \\
\hline High-taper gutta-percha (0.04-0.06) & $310(44.7)$ & $384(55.3)$ & $99(40.6)$ & $145(59.4)$ & $211(46.9)$ & $239(53.1)$ & 0.11 \\
\hline Intraoral camera & $148(21.3)$ & $548(78.7)$ & $41(16.8)$ & $203(83.2)$ & $107(23.7)$ & $345(76.3)$ & 0.035 \\
\hline Injection technique (Obtura) for canal obturation & $81(11.6)$ & $615(88.4)$ & $20(8.2)$ & $225(91.8)$ & $61(13.5)$ & $390(86.5)$ & 0.035 \\
\hline Central heating technique (Thermafil) for canal obturation & $80(11.5)$ & $616(88.5)$ & $24(9.8)$ & $24(90.2)$ & $56(12.4)$ & $395(87.6)$ & 0.3 \\
\hline Use of MTA for pulpotomy of young permanent teeth & $160(23.0)$ & $537(77.0)$ & $53(21.6)$ & $192(78.4)$ & $107(23.7)$ & $345(76.3)$ & 0.54 \\
\hline Use of MTA for DPC of young permanent teeth & $182(26.1)$ & $515(73.9)$ & $63(25.7)$ & $182(74.3)$ & $119(26.3)$ & $333(73.7)$ & 0.86 \\
\hline Use of MTA as an apical plug of young permanent teeth & 255 (36.6) & $442(63.4)$ & $81(33.1)$ & $164(66.9)$ & $174(38.5)$ & $278(61.5)$ & 0.15 \\
\hline Use of MTA in apicoectomy procedures & $121(17.4)$ & $575(82.6)$ & $32(13.1)$ & $213(86.9)$ & $89(19.7)$ & $362(80.3)$ & 0.04 \\
\hline
\end{tabular}

Table 2. Frequencies (Percentages) of the Use of New Endodontic Instruments and Techniques Separately in Relation to Academic Degree

\begin{tabular}{|c|c|c|c|c|c|c|c|c|c|}
\hline \multirow{2}{*}{ Question } & \multicolumn{2}{|c|}{$\begin{array}{c}\text { Total } \\
\text { (Male and Female) }\end{array}$} & \multicolumn{2}{|c|}{ General Practitioners } & \multicolumn{2}{|c|}{ Endodontists } & \multicolumn{2}{|c|}{ Other Specialists } & \multirow[b]{2}{*}{$\begin{array}{c}\text { P- } \\
\text { Value }\end{array}$} \\
\hline & Yes & No & Yes & No & Yes & No & Yes & No & \\
\hline & $\mathrm{N}(\%)$ & $\mathrm{N}(\%)$ & $\mathrm{N}(\%)$ & $\mathrm{N}(\%)$ & $\mathrm{N}(\%)$ & $\mathrm{N}(\%)$ & $\mathrm{N}(\%)$ & $\mathrm{N}(\%)$ & \\
\hline Surgical microscope & $7(1.0)$ & $683(99.0)$ & $4(0.7)$ & $588(99.3)$ & $1(2.0)$ & $48(98.0)$ & $2(4.1)$ & $47(95.5)$ & 0.056 \\
\hline Loop for magnification & $106(15.4)$ & $583(84.6)$ & $76(12.9)$ & $515(87.1)$ & $19(38.8)$ & $30(61.2)$ & $11(22.4)$ & $38(77.6)$ & $<0.001$ \\
\hline $\begin{array}{l}\text { Transillumination to detect cracks in } \\
\text { tooth structure }\end{array}$ & $132(19.2)$ & $555(80.8)$ & $106(18.0)$ & $483(82.0)$ & $17(34.7)$ & $32(65.3)$ & $9(18.4)$ & $40(81.6)$ & 0.02 \\
\hline Digital radiographic technique & $212(30.9)$ & $473(69.1)$ & $179(30.5)$ & $408(69.5)$ & $23(46.9)$ & $26(53.1)$ & $10(20.4)$ & $39(79.6)$ & 0.015 \\
\hline Electric motor for NiTi rotary files & $211(30.7)$ & $476(69.3)$ & 175 (29.7) & $415(70.3)$ & $30(61.2)$ & $19(38.8)$ & $6(12.5)$ & $42(87.5)$ & $<0.001$ \\
\hline $\begin{array}{l}\text { Ultrasonic device to dislodge posts } \\
\text { and cores or endodontic surgery }\end{array}$ & $148(21.4)$ & $542(78.6)$ & $106(17.9)$ & $486(82.1)$ & $37(75.5)$ & $14(28.6)$ & $7(14.3)$ & $42(85.7)$ & $<0.001$ \\
\hline High-taper gutta-percha (0.04-0.06) & $366(44.5)$ & $381(55.5)$ & $255(43.3)$ & $334(56.7)$ & $35(71.4)$ & $12(24.5)$ & $14(28.6)$ & $35(71.4)$ & $<0.001$ \\
\hline Intraoral camera & $148(21.5)$ & $541(78.5)$ & $131(22.2)$ & $460(77.8)$ & $8(16.3)$ & $41(83.7)$ & $9(18.4)$ & 40 (81.6) & 0.54 \\
\hline
\end{tabular}


Table 2. cont....

\begin{tabular}{|c|c|c|c|c|c|c|c|c|c|}
\hline \multirow{2}{*}{ Question } & \multicolumn{2}{|c|}{$\begin{array}{c}\text { Total } \\
\text { (Male and Female) }\end{array}$} & \multicolumn{2}{|c|}{ General Practitioners } & \multicolumn{2}{|c|}{ Endodontists } & \multicolumn{2}{|c|}{ Other Specialists } & \multirow[b]{2}{*}{$\begin{array}{c}\text { P- } \\
\text { Value }\end{array}$} \\
\hline & Yes & No & Yes & No & Yes & No & Yes & No & \\
\hline $\begin{array}{l}\text { Injection technique (Obtura) for } \\
\text { canal obturation }\end{array}$ & $79(11.5)$ & $610(88.5)$ & $66(11.2)$ & $525(88.8)$ & $7(14.3)$ & $42(85.7)$ & $6(12.2)$ & $43(87.8)$ & 0.79 \\
\hline $\begin{array}{l}\text { Central heating technique } \\
\text { (Thermafil) for canal obturation }\end{array}$ & $79(11.5)$ & $610(88.5)$ & $73(12.3)$ & $519(87.7)$ & $3(6.1)$ & $46(93.9)$ & $3(6.3)$ & $45(93.8)$ & 0.21 \\
\hline $\begin{array}{l}\text { Use of MTA for pulpotomy of young } \\
\text { permanent teeth }\end{array}$ & $157(22.8)$ & $533(77.2)$ & $122(20.6)$ & $470(79.4)$ & $27(55.1)$ & $22(44.9)$ & $8(16.3)$ & $41(83.7)$ & $<0.001$ \\
\hline $\begin{array}{l}\text { Use of MTA for DPC of young } \\
\text { permanent teeth }\end{array}$ & $179(25.9)$ & $511(74.1)$ & $148(25.0)$ & $444(75.0)$ & $23(46.9)$ & $26(53.1)$ & $8(16.3)$ & $41(83.7)$ & 0.86 \\
\hline $\begin{array}{l}\text { Use of MTA as an apical plug of } \\
\text { young permanent teeth }\end{array}$ & $255(37.0)$ & $435(63.0)$ & $205(34.6)$ & $387(65.4)$ & $45(91.8)$ & $4(8.2)$ & $5(10.2)$ & $44(89.8)$ & $<0.001$ \\
\hline $\begin{array}{l}\text { Use of MTA in apicoectomy } \\
\text { procedures }\end{array}$ & $119(17.3)$ & $570(82.7)$ & $78(13.2)$ & $514(86.6)$ & $35(72.9)$ & $13(27.1)$ & $6(12.2)$ & $43(87.8)$ & $<0.001$ \\
\hline
\end{tabular}

Table 3. The Usage Rate of New Endodontic Instruments and Techniques Separately for the Year of Graduation

\begin{tabular}{|c|c|c|c|c|}
\hline Year of Graduation & Never $(\%)$ & Sometimes (\%) & Mostly (\%) & Always (\%) \\
\hline $1968-1978$ & 16.7 & 66.7 & 13.9 & 2.8 \\
\hline $1979-1987$ & 12.7 & 74.5 & 12.7 & 0.0 \\
\hline 1988-1997 & 8.3 & 82.8 & 8.3 & 0.6 \\
\hline $1998-2011$ & 15.5 & 73.4 & 10.2 & 0.8 \\
\hline
\end{tabular}

This is not significant! Table $\mathbf{3}$ shows the usage rates of new endodontic instruments and techniques separately for graduation year, demonstrating no significant relationship between the two variables $(\mathrm{p}=0.29)$.

Regarding the use of MTA, the results of the present study showed that it is more frequently used as an apical plug in young permanent teeth; it is least frequently used in apicectomy procedures.

\section{DISCUSSION}

The present study evaluated the use of new endodontic instruments and techniques by general dental practitioners and specialists.

At present endodontics is associated with new instruments and techniques and great advances have been made in the endodontic materials and instruments since 1990. The new techniques available now include electric motors with NiTi rotary systems, apex locators, digital radiography sensors, microscopes and ultrasonic units. Nowadays postgraduate programs are designed based on these new instruments and techniques in many countries [20].

New instruments and techniques make the treatment outcome predictable, decrease duration of treatment and treatment sessions and simplify the treatment procedures [6]. Several studies have shown that proper and correct use of instruments along with the use of new instruments, and practitioners' experience, expertise, and knowledge result in a success rate of $90 \%$ in endodontic treatment. It is obvious that shortcomings in any of the steps above might result in the failure of endodontic treatment [15]. Studies have shown that more than $50 \%$ of teeth do not receive proper endodontic treatment and approximately $30-50 \%$ of root- filled teeth have radiographic signs of apical periodontitis [16]. Despite the great number of reports about incomplete and improper root canal treatment, few studies have evaluated factors affecting the quality of root canal treatment. A review study by Peciuliene et al. in 2009 showed that there are differences between the daily practice of dental practitioners and the standards promulgated by educational programs offered at universities in different countries. Many dental practitioners may violate the basic principles of endodontic treatment [16, 19].

The results of the present study showed that $74.6 \%$ of Iranian dental practitioners under study sometimes use new endodontic instruments and techniques and $14.1 \%$ never use them. The results showed a significant relationship between gender and usage rate of new endodontic instruments and techniques, with females making greater use of such instruments and techniques. The results of the present study are inconsistent with those of a study carried out by Tay et al. in 2008 in New Zealand, in which males used new techniques, including intraoral cameras, more frequently than females [14]. The difference might be attributed to the fact that female dental practitioners take part in continuing and on-the- 
job training courses more frequently than males, which results in the improvement of their knowledge and increases the frequency of the use of new techniques. The results of the present study showed a significant relationship between the dental practitioners' experience (general practitioner vs. specialist) and the rate of the use of new endodontic techniques. This indicates that there is an increase in the frequency of the use of new endodontic instruments and techniques with an increase in the knowledge and experience of dental practitioners.

The results of the present study showed that $50.1 \%$ of respondents used NiTi rotary files for root canal preparation. Reith and Bjorndal in 2005 in Denmark reported a 10\% usage rate for NiTi rotary files [10]. Lee et al. reported that $28 \%$ of their subjects used NiTi rotary files in the United States in 2009 [15]. Slaus and Bottenberg, in 2002 reported $47 \%$ and $50 \%$ usage rates for NiTi hand files [20]. Other studies have reported usage rates of $1.6-22 \%$ for NiTi rotary files $[10,15,17,21]$.

Studies have shown that NiTi files decrease errors and improve treatment outcomes compared to stainless steel hand instruments. It is obvious that use of rotary systems decreases the time needed for canal debridement and as a result decrease the number of treatment sessions [18].

Apex locators were used by $46.3 \%$ of the participants in the present study, ranking the second highest usage after NiTi rotary files, which was higher than that reported by some other studies [10].

In a study carried out by Lee, et al. in $2009,72.5 \%$ of the participants used apex locators, which was the highest usage rate. However, Bjorndal and Reith reported a rate of $15 \%$ in 2005 in Denmark, which is attributed to the lack of registered endodontists in Denmark until 2005 and a lack of adequate education for other undergraduate dental students at universities and also the lack of continuing training courses $[10,15,18]$.

The results of the present study showed that only $1 \%$ of the participants used surgical microscopes. More than $50 \%$ of the dental practitioners under study never used microscopes or lenses or seldom used them, which might be a reason for the fact that $75 \%$ of general dental practitioners never or seldom prepare or obturate the fourth root canal of maxillary first molars [16]. The low rate of the use of surgical microscopes in the present study compared to that reported by Lee et al in 2009 in the United States (45.3\%) might be attributed to the out-of-date educational programs, lack of endodontic expertise by general dental practitioners and the high cost of such microscopes in Iran. Digital radiographic techniques were used by $30.9 \%$ of general dental practitioners and $46 \%$ of endodontists under study in the abovementioned study. Brian and Williamson reported that $19.7 \%$ of Indian dental practitioners used digital radiographic techniques in 2007 [9]; the rate was $73 \%$ of the general practitioners in the present study. Brady reported a rate of $36 \%$ for the use of digital radiographic techniques in 2007 in Hawaii, which is consistent with the results of the present study [22]. The high price of the equipment might be a reason why some dental practitioners do not use it. Lee et al. in 2009 reported a rate of $72.5 \%$ in the United States, which might be attributed to the higher economic potential of American dental practitioners and the better education they have received [15].

Sharland et al reported usage rates of $65 \%$ for intraoral cameras, $18 \%$ for digital cameras and $12 \%$ for intraoral digital video cameras by dental practitioners in 2004 in England [23]. Morse et al. in 2010 in England reported usage rates of $59 \%$ for digital cameras, $34 \%$ for intraoral cameras and $19 \%$ for video cameras [24]. In a study by Tay et al. in 2008, intraoral cameras had the highest usage rate with $49.6 \%$ [14].

The differences between the results of the present study and those of the three above-mentioned studies might be attributed to out-of-date academic instructions, paucity of continuing training courses and the high equipment prices.

The usage rate for ultrasonic units to dislodge posts and cores or endodontic surgeries in the present study was $21.6 \%$, which is much lower than that reported by Lee et al. in 2009 in the United States (97.8\%) [15]. The low usage rate of this equipment in Iran might be attributed to the lack of adequate training courses and the resultant unfamiliarity of Iranian dental practitioners with the equipment, and the possible complications which arise during the clinical application, including dentinal cracks. Injection and Thermafil canal obturation techniques were used by only $11.5 \%$ of respondents in the present study. Bjorndal and Reith in 2005 in Denmark reported that $19 \%$ of the dental practitioners under study obturated root canals with heated gutta-percha [10]. Slaus and Bottenberg reported in 2002 that lateral compaction was the principal technique to obturate root canals by $60 \%$ of Finnish dental practitioners [20]. Lee et al. in 2009 reported that lateral compaction was the principal technique used by American dental practitioners [15].

The low usage rate of injection and Thermafil obturation techniques in all the above-mentioned studies might be attributed to possible errors during obturation, complexity of the techniques and the need for more equipment compared to the ease and simplicity of the lateral compaction technique. In the same context, it is worth mentioning that in most universities lateral compaction techniques are the principal obturation technique used.

MTA was used by $54.8 \%$ of dental practitioners in the present study. MTA was introduced to endodontics during 1990s by Torabinejad [25], which revolutionized this branch of dentistry. Peciuliene reported in 2009 that MTA was the most commonly used material by dental practitioners as a root-end filling material [17].

In the present study, ethyl chloride was used for the cold test of pulp vitality by $23.5 \%$ of the participants; loops were used for magnification by $15.2 \%$; transillumination was used to diagnose cracks in the tooth structure by $19.3 \%$; electric motors were used for NiTi rotary files by $30.7 \%$; and hightaper gutta-percha was used by $44.7 \%$. The results of the present study cannot be compared with those of other studies since these are no similar studies. The results of the present study show that in some cases the usage rates of new endodontic instruments are less than what is expected. 


\section{CONCLUSION}

The results of the present study showed that despite significant advances in the manufacture and design of new endodontic instruments and techniques, the use and acceptance of such instruments and techniques by dental practitioners are not at an acceptable level.

\section{RECOMMENDATIONS}

Considering the results of the present study, it is suggested that general dental practitioners be properly and adequately instructed in the new endodontic instruments, materials and techniques and conferences and continuing training programs be designed, offered and held to improve and enhance the scientific and practical capabilities of dental practitioners.

It is also suggested more comprehensive questionnaires with questions about the qualitative and quantitative use of new endodontic materials, instruments and techniques be prepared and used.

\section{ACKNOWLEDGEMENT}

None declared.

\section{CONFLICT OF INTEREST}

None declared.

\section{SUPPLEMENTARY MATERIAL}

Supplementary material is available on the publisher's web site along with the published article.

\section{REFERENCES}

[1] Kenneth MH. Pathways of the pulp. $10^{\text {th }}$ ed. USA: Mosby Co 2011; chap 6: p.1242.

[2] Pinkham J, Casamassimo P, McTigue D, Fields H, Nowak A. Pediatric dentistry infancy through adolescence. $4^{\text {th }}$ ed. USA: Saunders Co 2005; pp. 577-88.

[3] Shahravan A, Rahimi H, Eghbal M, Movahedian A, Moradi S. A comprehensive reference of root canal preparation instruments and techniques. $1^{\text {st }}$ ed. Tehran: Moalefi Publications 2005; pp. 121-58, 222-45, 256- 65

[4] Silva MR, Biffi JC, Mota AS, Fernandes NAJ, Neves FD. Evaluation of intracanal post removal using ultrasound. Braz Dent J 2004; 15(2):119-26.

[5] Tabari K, Esna AM. Maintaining tooth pulp vitality with MTA. $1^{\text {st }}$ ed. Tehran: Noure Danesh Publications 2005; pp. 201-47, 202-48.

[6] Molven O, Halse A, Riordan PJ. Prevalence and distribution of root-filled teeth in former dental school patients: follow-up after 10-17 years. Int Endod J 1985; 18(4): 247-52.
[7] Casella G, Ferlito S. The use of mineral trioxide aggregation in endodontics. Minerva Stomatol 2006; 55(3): 123-43.

[8] Bogen G, Kim JS, Bakland LK. Direct pulp capping with mineral trioxide aggregate: an observational study. J Am Dent Assoc 2008; 193(3): 305-15: quiz 305-15.

[9] Brain JN, Williamson GF. Digital radiography in dentistry: a survey on Indian dentists. Dentomaxillofac Radiol 2007; 36(1):18-23.

[10] Bjorndal L, Reit C. The adoption of new endodontic technology amongst Danish general dental practitioners. Int Endod 2005; (38) $1: 52-8$.

[11] Zho XY, Dong Q, Wang SM, Zhang CF. Comparison of clinical effect of different tapered gutta-percha root filling with warm vertical condensation. Hua Xi Kou Qiang Yi Xuue Za Zhi 2008; 16(5): 505-8.

[12] De-Deus G, Gurgel-FED, Magalhaes KM, Coutinho-FT. A laboratory analysis of gutta-percha-filled area obtained using Thermafil system B and lateral condensation. Int Endod J 2006; 39(5): 37883.

[13] Arbab-CR, Vulcain JM. Undergraduate teaching and clinical use of rotary nickel-titanium endodontic instruments: a survey of French dental schools. Int Endod J 2004; 37(5): 320-4.

[14] Tay Kl, Wu JM, Yew MS, Thomson WN. The use of newer technologies by New Zealand dentists. N Z Dent J 2008; 104(3): 104-8.

[15] Lee M, Winkler J, Hartwell G, Stewart J, Caine R. Current trends in endodontic practice : emergency treatments and technological armamentarium . J Endod 2009; 35(1): 35-9.

[16] Peng L, Ye L, Tan H, Zhou X. Outcome of root canal obturation by warm gutta-percha versus cold lateral condensation: a meta-analysis. J Endod 2007; 33(2): 106-9.

[17] Peciuliene V, Maneliene R, Drukteinis S, Rimkuviene J. Attitudes of general dental practitioners towards endodontic standards and adaption of new technology: a literature review. Stomatologija 2009; 11(1): 11-4.

[18] Koch M, Eriksson HG, Axelsson S, Tegelberg A. Effect of educational intervention on adoption of new endodontic technology by general dental practitioners: a questionnaire survey. Int Endod J 2009; 42(4): 313-21.

[19] Gerland N, Glickman. 21th Century Endodontics. J Am Dent Assoc 2001; 131(1): 395-465

[20] Slaus G, Bottenberg P. A survey of endodontic practice amongst flemish dentists. Int Endod J 2002; 35(9): 759-67.

[21] Parashos P, Messer HH. Questionnaire survey on the use of votary nickel-titanium endodontic by Australian dentists. Int Endod J 2004; 37(4): 249-59.

[22] Brady DT. Digital radiography: a survey of dentists in Hawaii. Hawaii Dent J 2007; 38(4): 10, 12-3.

[23] Sharland MR, Burke FJ, McHugh S, Walmsley AD. Use of dental photography by general dental practitioners in Great Britain. Dent Update 2004; 31(4): 199-202.

[24] Morse GA, Haque MS, Sharland MR, Burke FJ. The use of clinical photography by UK general dental practitioners. Br Dent J 2010; 208(1): E1; discussion 14-5.

[25] Ford TR, Torabinejad M, Abedi HR, Bakland LK, Kariyawasam SP. Using mineral trioxide aggregate as a pulp-capping material. J Am Dent Assoc 1996; 127(10): 1491-4. 